\title{
O Saber docente sobre Educação Ambiental
}

\author{
Teaching about Environmental Education
}

Patrícia Mendes Calixto $\left.{ }^{1 *}\right)$

Ivana de Campos Ribeiro ${ }^{2}$

\section{Resumo}

Este trabalho compreende a análise de um processo de formação continuada realizado com professores da educação básica, da região carbonífera do Rio Grande do Sul. O objetivo foi identificar quais saberes compreendem o trabalho docente sobre educação ambiental. Buscamos na prática contribuir com a reflexão sobre práticas de educação ambiental na escola. A atividade foi organizada em formato de curso, dividido em quatro (4) etapas nas quais trabalhou-se os Princípios da Educação Ambiental, as Políticas da Educação Ambiental para a escola, as Interfaces da Educação Ambiental na escola e Projetos de Educação Ambiental na Escola. O curso contou com a participação de professores oriundos da escola básica, dos quais a maioria já havia realizado atividades ambientais, embora este não tenha sido um requisito para realizarem o curso. Dentre os ministrantes do curso, especialistas e pesquisadores da área os quais além de compartilhar suas experiências trouxeram a motivação, a reflexão e ideias criativas de introdução do tema transversal na escola. A pesquisa teve uma abordagem qualitativa e foi realizada durante o processo de formação continuada o qual revelou que os docentes participantes, conhecem pouco sobre os referenciais teóricos da Educação Ambiental e defendem a introdução de uma disciplina específica sobre este tema na escola. Identificamos resistências profundas em integrar os conhecimentos científicos e ainda, de conceber uma escola com um espaço de formação de sujeitos a partir dos valores humanos. Entendem que valores ensina-se apenas em casa. Entretanto, todos consideraram a experiência de formação continuada válida e declararam ser esta uma ação pioneira na região pela abordagem dada exclusivamente ao âmbito escolar.

Palavras-chave: educação ambiental, formação de professores, políticas ambientais

\section{Abstract}

This work includes the analysis of a continuing education process conducted with teachers of basic education, the coal region of Rio Grande do Sul. The goal was to identify which knowledge understand the teaching work on environmental education.

1 DRA.; Educação Ambiental; Universidade Federal do Rio Grande, FURG, Brasil; Professora do Instituto Federal de Educação, Ciência e Tecnologia Sul-Rio-Grandense; Endereço: Instituto Federal Sulriograndense. Rua General Balbão, 81, Centro. CEP: 96745000 - Charqueadas, RS - Brasil; E-Mail: patricia.tutoria@gmail.com

(*) Autor para correspondências

2 Dra.; Ecologia e Recursos Naturais; Universidade Federal de São Carlos, UFSCAR, Brasil; Pesquisadora Colaboradora do LABEEST - Laboratório de Estudos do Estresse, IB, Departamento de Biologia Estrutural e Funcional da UNICAMP, sendo ainda membro do LEL - Laboratório de Estudos do Lazer, Departamento de Educação Física, I.B. UNESP - Rio Claro e do Laboratório; Endereço: Instituto Brasileiro de Educação para a Vida, Instituto Brasileiro de Educação para a Vida. Av. 5-A, 352, Cidade Nova. CEP: 13506000 - Rio Claro, SP - Brasil; E-Mail: ivana.ibev@gmail.com

\begin{tabular}{llllll}
\hline Ambiência & Guarapuava (PR) & v.14 n.2 & p. 378-389 & Maio/Ago 2018 & ISSN $1808-0251$
\end{tabular}


We seek in practice contribute to the reflection on environmental education practices in school. The activity was organized in the course format, divided into four (4) steps in which we worked on the Principles of Environmental Education, the Environmental Education Policies for school, the interfaces of environmental education in school and Environmental Education Projects in School. The work included the participation of teachers from primary schools, most of which had already conducted environmental activities, although this has not been a requirement to conduct the course. Among the worshipers of the course, experts and researchers in the field that in addition to sharing their experiences brought motivation, reflection and creative ideas for introducing the cross-cutting theme in school. The research carried out during the training process revealed that participants teachers, know little about the theoretical framework of environmental education, advocate the introduction of a specific discipline on the subject in school. We identify deep resistance to integrate scientific knowledge and also to design a school with a space for formation of subjects from human values. They understand that value is taught only at home. However, all they considered valid continuing education experience and declared that this is a pioneering initiative in the region for the approach given exclusively to the school environment.

Keywords: environmental education, teacher training, environmental policies

\section{O Começo da Trilha}

A educação para a sustentabilidade decorre de uma busca por transformações de comportamento e atitudes que estimule o desenvolvimento do sendo crítico dos estudantes. Este é um fator relevante para a mudança paradigmática, pois envolve repensar nossas relações com o consumo, com a ciência e o desenvolvimento de tecnologias sociais que representem mudanças nas comunidades. É relevante ainda para que sejamos solidários e busquemos superar a depredação da diversidade ambiental. Foi para contribuir com essa concepção que planejamos um curso de formação continuada para professores da educação básica. Tendo como tema central a Educação Ambiental (EA) focamos nossos esforços em compartilhar com os participantes os princípios, a legislação e experiências que pudessem ser representativas para eles.

A análise teve como referencia a EA transformadora e crítica de Loureiro (2004). Esta caracteriza-se por uma abordagem na qual o diálogo entre os saberes é fundamental. Da mesma forma, a criticidade em relação ao modo como vivemos deve estar presente em todos os momentos. Além disso, vislumbra a democracia como condição para uma sociedade sustentável. O pesquisador ainda destava a necessidade da participação social bem como a transformação dos valores sociais para busca da equidade social.

Este trabalho é uma experiência desenvolvida a partir da demanda apresentada pela comunidade de professores da região a um grupo de pesquisa do IFSul. A região carbonífera caracteriza-se pelo coletivo de seis municípios cuja economia baseia-se nas atividades de comércio e serviços.

A pesquisa teve início a partir de uma atividade extensionista denominada "Diálogos sobre Pesquisa" a qual foi realizada em uma escola de ensino básico. Este evento precede a maior mostra científica da região, cujo objetivo é apresentar os trabalhos de pesquisa desenvolvidos pelos educadores e seus estudantes dos municípios abrangidos. Portanto, este evento serve como um espaço de preparação para esta feira. Ali são ofertadas oficinas sobre elaboração de projetos, 
produção de pôster, técnicas de apresentação de trabalhos orais e escritos, além de temas específicos como a Educação Ambiental.

Durante o desenvolvimento da oficina de Educação Ambiental, com educadores da escola básica, fez-se a divulgação do grupo de pesquisa em Educação Ambiental e das ações periódicas de estudos sobre este tema. Neste momento, o grupo de participantes solicitou um trabalho mais amplo, no qual pudesse se trabalhar não apenas os aspectos práticos, mas sobretudo os teóricos. Atendendo a esta solicitação foi idealizado o curso de Educação Ambiental para professores da escola básica. Foram abertas, inicialmente 20 vagas e devido a demanda, estas foram ampliadas para 35.

Este curso, caracterizado, portanto, como uma atividade extensionista, apresenta um grande desafio no campo prático, isto é, abrir as portas da instituição proponente à comunidade revelando o que faz e o que pensa sobre determinados temas. Colocamo-nos assim como referência para um tema ainda pouco explorado na região.

Baseando-nos nas análises de Freire (2006), compreendemos esse momento como um processo dialógico com o grupo participante, onde também buscamos conhecer a sua realidade vivida, pois esta é determinante para as escolhas feitas, para identificação dos problemas e possíveis encaminhamentos.

Ao longo desse processo, buscamos identificar quais práticas são denominadas como educativas ambientais, quais as referências teóricas são usadas por este grupo, quais interesses permeiam os projetos por eles em desenvolvimento e o que buscam em atividades como esta que está sendo ofertada. Sendo assim, o grupo também participou ativamente, apresentando suas experiências, de modo que pudéssemos debater, sem verticalizar a relação entre os participantes e os organizadores.

Diante deste cenário, o grupo de pesquisa analisou o seguinte problema: quais saberes educativos ambientais permeiam o trabalho do educador da escola básica? Este entendimento é relevante, especialmente para que pudéssemos identificar como os participantes identificam os problemas ambientais mais difíceis de serem resolvidos. Além disso, nos ajuda a compreender as propostas de trabalhos caracterizados no eixo meio ambiente que são encaminhados à mostra científica anual.

Assim, a seguir apresentamos nossas referencias teóricas em relação ao tema, pois foi a partir delas que analisamos as práticas e discursos dos educadores participantes do curso.

\section{O que é o saber ambiental?}

Partimos do conceito de saber ambiental proposto por Leff (2009). Este autor traça uma reflexão epistemológica das distintas ciências para apresentar a tese de que a relação entre os distintos conhecimentos constituem o saber ambiental. A interdisciplinaridade é, portanto, o ponto de partida para a unificação da ciência e só assim, poder explicar os sistemas socioambientais complexos. Sobre isso ele diz:

O saber ambiental problematiza o conhecimento fragmentado em disciplinas e a administração setorial do desenvolvimento, para constituir um campo de conhecimento teóricos e práticos orientado para a rearticulação das relações sociedade-natureza. Este conhecimento não se esgota na extensão dos paradigmas da ecologia para compreender a dinâmica dos processos socioambientais, nem se limita a um componente ecológico nos paradigmas atuais do conhecimento (LEFF, 2009, p.145) 
É sobre essa possibilidade apontada pelo autor que nos debruçamos para planejar as ações educativas ambientais. Sabemos que o trabalho solitário e isolado, mesmo que com objetivos claros, não alcança êxito.

Compreender o mundo contemporâneo, portanto é fundamental. Já muito tem sido discutido sobre a presença das relações antagônicas entre os interesses econômicos e os aspectos ambientais. As marcas deixadas no espaço representam, cada vez mais, uma relação menos cordial entre a sociedade e a natureza. Entende-se aqui, por natureza, o objeto de conhecimento da biologia e a dinâmica dos ecossistemas (LEFF, 2009).

Assim, analisar, refletir e propor novos modelos de interação fazem parte do cotidiano da escola, considerando esta apenas um dos espaços para tal atividade. Entretanto, é salutar que os educadores, juntamente de seus estudantes construam em conjunto esse processo de desenvolvimento de um sujeito ecológico, como propõe Carvalho (2008). O sujeito ecológico é aquele com capacidade e sensibilidade para identificar e compreender os problemas ambientais, mobilizando-se e comprometendo-se com as decisões relacionadas ao ambiente equilibrado. Chamamos aqui de problemas ambientais os eventos que podem alterar o equilíbrio dos ecossistemas e por consequência interferir na qualidade de vida das pessoas.

Sendo a escola um dos espaços, como já destacamos, onde é possível se repensar as relações mantidas com o ambiente, é para ela que pensamos em novas propostas de lidar com essa questão. Questão esta bastante complexa uma vez que envolve aspectos políticos, econômicos, sociais e até culturais. Como apontam Garcia e Priotto (2009) é preciso construir novas atitudes e critérios baseados em princípios sustentáveis para que seja possível conceber uma sociedade mais justa e igualitária.

Mas, compreende-se que para um trabalho como esse, além desse ideal social há necessidade de compreendermos o que é o saber ambiental. Considerando as proposições de Leff (2009) que avalia a necessidade de novos enfoques metodológicos que contribuem para a apreensão de processos de causas múltiplas, o saber ambiental é compreendido como uma categoria sociológica em que comportamentos, valores, saberes e potenciais produtivos são regidos pelas questões ecológicas. Como por exemplo, as potencialidades e fragilidades de um ambiente para fins exploratórios.

Por essas razões as propostas relacionadas a temática ambiental, devem, necessariamente, considerar a integração dos saberes, bem como a organização do conhecimento de modo interdisciplinar, para que as práticas escolares possam, efetivamente, estarem voltadas para a sustentabilidade. Isto porque os problemas ambientais apresentam interdependência e origem multicausal.

Nesta relação entre a questão da integração dos saberes e as práticas, identificar em quais os saberes docentes estão ancoradas as práticas ambientais escolares são fundamentalmente relevantes para esta análise. Para tanto, nos apoiamos nos referenciais que destacamos a seguir.

\section{O saber docente}

Os saberes necessários a prática educativa ambiental constituem um conjunto de conhecimentos que contribuem para a construção de uma consciência que reconheça a diversidade do mundo atual, favorecendo a compreensão do ambiente como constituído não apenas por ecossistemas frágeis, mas organizados e atravessados por um processo histórico que nem sempre 
foi satisfatório à coletividade (TARDIF, 2006). Neste sentido, habilidades para reconhecer a conexão entre os componentes do mundo, ser flexível e adaptar-se a novas ideias são requisitos para desenvolver a criticidade e atuar de modo mais equilibrado.

Assim, essa pesquisa buscou compreender e analisar o conhecimento científico presente nos saberes docentes sobre as questões ambientais. Nosso objetivo foi contribuir para o planejamento e reorientação da prática pedagógica. Para que junto aos seus estudantes, como propõem os autores supracitados possam desenvolver uma nova mentalidade coletiva, na qual novas atitudes e princípios sustentáveis estejam presentes.

Buscamos ainda relacionar os discursos educativos ambientais a um espaço físico concreto, isto é o espaço geográfico. Desta forma, permeou todo o trabalho, este conceito, proposto por Santos (2006, p. 39):

É formado por um conjunto indissociável, solidário e também contraditório, de sistemas de objetos e sistemas de ações, não considerados isoladamente, mas como um quadro único na qual a história se dá. No começo era natureza selvagem, formada por objetos naturais, que ao longo da história vão sendo substituídos por objetos fabricados, objetos técnicos, mecanizados e, depois, cibernéticos fazendo com que a natureza artificial tenda a funcionar como uma máquina.

Nesta proposição, observamos que o espaço geográfico é construído socialmente, portanto, as crenças, os modos de produção e a conjuntura coletiva determinam o modo como o espaço é transformado. Portanto, estar apto a levar os estudantes a observar, analisar e perceber as contradições do espaço torna a aprendizagem mais autêntica.

Propomos, assim, durante este curso uma avaliação das práticas no campo subjetivo, tanto quanto no campo do espaço físico. Como analisa Suertegaray (2001), o espaço geográfico manifesta a produção humana e, por isso, tem sua estrutura e funcionamento modificados ao longo da história: "é a coexistência do passado e do presente ou de um passado reconstituído no presente". Refletir sobre como e porquê essas modificações ocorrem é o papel do educador ambiental. Para quem trabalha com EA, é necessário o entendimento de que o espaço ocupado funciona por meio de relações entre os objetos ali presentes e as ações humanas. É nesta relação que moldamos o mundo. Para o educador, compreender que não basta trabalhar apenas para o campo subjetivo, embora não indispensável, é relevante para que o sujeito em formação reconheça o funcionamento do espaço físico e possa refletir sobre as contradições existentes e ainda, possa tomar decisões que sejam mais favoráveis do ponto de vista coletivo.

Partindo dessa ideia, sugerimos uma série de reflexões ao longo do processo de formação, de modo que fossemos avaliar nossas práticas de forma criteriosa, colocando uma lupa sobre cada ação. Um dos direcionamentos foi identificar e conhecer as variáveis envolvidas em uma atividade educativa ambiental, como por exemplo, conceber o mundo globalizado, trazer a questão da solidariedade e da fraternidade nas relações humanas (RIBEIRO; SCHARTZ, 2017) e pensar em um novo modo de lidar com o consumo.

Com base nessas variáveis verificamos a necessidade de trabalhar mergulhados na cidadania crítica, reflexiva e participativa para que fossem possíveis as tomadas de decisão mais acertadas. Assim, analisou-se os conceitos relacionados a EA, em que houvesse compreensão das problemáticas socioambientais na qual estão inseridos; para que adquiríssemos conhecimentos e criássemos um grupo local de multiplicadores com habilidades para organizar os movimentos dentro de suas escolas e por fim, fortalecêssemos as políticas locais da EA na escola. A seguir apresentamos a construção dessa etapa. 


\section{Construindo o horizonte da pesquisa}

Essa pesquisa teve uma abordagem de cunho qualitativo. Todos os dados e observações feitas foram analisadas a luz da subjetividade emanada pelos participantes em interação com os pesquisadores. Os levantamentos foram feitos através de entrevistas, questionários e produção de mapas mentais. Nessa perspectiva, o fenômeno é analisado de forma integral, isto é contextualizando como sugere Turato (2003).

Começamos esse trabalho com reflexões e ações empreendidas ao longo do processo durante um evento que foi realizado no Dia Mundial do Meio Ambiente. Foi um modo de comunicar a comunidade local o início das atividades do grupo de pesquisa sobre EA. No mesmo dia, foram abertas as inscrições para participação no curso "Formação continuada de professores em Educação Ambiental: contribuições para a introdução do tema na escola básica”.

O curso foi dividido em quatro etapas, nas quais foram desenvolvidas as seguintes temáticas: 1) Princípios da Educação Ambiental; 2) Políticas da Educação Ambiental para a escola; 3) Interfaces da Educação Ambiental na escola e 4) Projetos de Educação Ambiental na Escola.

Considerando a indissociabilidade entre o ensino, a pesquisa e a extensão, buscamos integrar as ações de modo a favorecer o desenvolvimento crítico e mais amplo das questões ambientais. Conforme apontam Moita e Andrade (2009, p.269):

(...) se considerados apenas em relações duais, a articulação entre o ensino e a extensão aponta para uma formação que se preocupa com os problemas da sociedade contemporânea, mas carece da pesquisa, responsável pela produção do conhecimento científico. Por sua vez, se associados o ensino e a pesquisa, ganha-se terreno em frentes como a tecnologia, por exemplo, mas se incorre no risco de perder a compreensão ético-político-social conferida quando se pensa no destinatário final desse saber científico (a sociedade).

Assim, concordando com os autores citados e trabalhando com a integração das três vertentes buscamos compreender como o fenômeno, caracterizado aqui como saber docente, baseandonos em Tardif (2006), é externalizado na prática do ensino por esses profissionais. Além disso buscamos atender uma demanda social em relação a formação continuada de professores através de uma ação extencionista. Buscamos assim, a aproximação da academia com a comunidade.

A organização de todo processo ocorreu em vinte encontros de duas horas, ao longo de dez meses. Neles realizou-se leituras acerca de temas relacionados a educação ambiental, debates, atividades práticas que poderão orientar os professores a trabalhar com seus estudantes, além do compartilhamento de muitas experiências com o grupo. Também foram realizadas atividades diversas para a coleta de dados para realização de análise qualitativa, como entrevista semiestruturada, questionário e mapas mentais.

O detalhamento de todos esse caminho está detalhado na sequencia.

\section{Estabelecendo reflexões sobre o caminho percorrido}

Processos de formação continuada, especialmente com professores são um grande desafio para qualquer mediador. Primeiro porque o tempo limitado e as grandes questões que são trazidas à pauta requer disciplina para não desviarmos do foco. Em segundo lugar, porque quando abrimos espaços a toda a comunidade interessada temos uma turma que o perfil varia entre o curioso, a 
formandos, a recém formados, a profissionais das áreas de conhecimento mais distintas e também àqueles que estão em busca de uma certificação mínima exigida pelo empregador. Ao mesmo tempo, tudo isso demonstra a emergência de espaços multiplicadores, pois percebemos que há necessidades latentes nas escolas da região.

Ao longo dos encontros refletimos sobre a postura e o novo modelo de profissional que atualmente exige-se para escola. As demandas sociais refletem uma multiplicidade de saberes que tornam cada vez mais complexo o nosso papel. Os educadores precisam perceberem-se como agentes importantes na educação para a sustentabilidade, onde analisa-se, elabora-se e aplica-se as novas ideias em uma construção coletiva. Não há trilha fácil nesse caminho, há obstáculos de naturezas diversas, como a ausência de tempo e espaço na agenda semanal para estudos, pouco ou nenhum apoio institucional, carga horária alta, além de complementação de horas em escolas situadas em regiões geográficas distantes entre si.

Percebeu-se que, apesar de a conjuntura na qual esses profissionais estão inseridos dificultarem a prática entendida como ideal, há motivação para continuar, qualificar-se, pensar em alternativas para superar as adversidades. A própria participação no curso demonstrou isso, já que as reuniões ocorriam a noite e alguns dos participantes deslocavam-se cerca de $140 \mathrm{~km}$ para chegarem ao campus.

Para compreender, portanto, como pensam e como fazem EA na escola, coletamos informações a partir das seguintes atividades: uma escrita livre, na qual o docente deveria abordar as dificuldades encontradas em seu espaço de trabalho para executar ações relacionadas a EA.

Analisamos nessa atividade recorrentes registros obre a ausência de valorização, de colaboração, respeito entre os pares, desrespeito entre colegas e sobretudo por parte da gestão escolar com os profissionais quando esses deixam de ser apoiados, inclusive diante das famílias dos seus estudantes. Observou-se que os fatores levantados estão diretamente relacionados as condições de trabalho onde as relações de poder acentuam o estresse do trabalhador da educação.

Os professores, como qualquer outro profissional, desejam um espaço de convivência harmonioso, de encontro entre seres que buscam, através do conhecimento científico, a melhoria da vida. No entanto, verificamos que, as contradições inerentes ao mundo objetivo comprometem a atuação, o interesse e a motivação. É a sobrecarga de horas de trabalho, como já dissemos antes, somadas as distâncias percorridas entre as escolas e os conflitos inerentes a profissão, como a relação com a família dos estudantes e, evidentemente entre os próprios pares.

Então, diante deste panorama nos questionamos: como motivar os educadores a ter posturas reflexivas ou de engajamento em questões socioambientais considerando o seu complexo e contraditório espaço de atuação? Ribeiro (2009) aponta para que busquemos profundamente por elementos que estimulem a consciência ambiental:

Talvez a Psicologia Ambiental ou linhas de Educação Ambiental mais profundas, seguindo os caminhos da Ecologia Profunda propagada pelo filósofo e ambientalista Arne Naess (1990) ou a propósito da Educação Ambiental de Corpo\&Alma, pudessem cumprir esta função (RIBEIRO, 2013, p.153-154).

Assim, a Educação Ambiental de Corpo\&Alma (RIBEIRO, 2011), se apoia em uma definição mais ampla sobre o conceito de ambiente, incorporando as dimensões representadas pelo indivíduo em seus aspectos biopsíquicos, as relações sociais, interpessoais e os ambientes natural e construído, os quais se inter-relacionam e se interinfluenciam. 
Quando investigou-se os saberes docentes sobre as questões ambientais para caracterizar o trabalho feito nas escolas, verificamos que, de modo geral, as atividades ocorrem de modo isolado e pautadas em uma agenda ecológica, isto é, observando datas comemorativas, como o "Dia da Árvore”, o “Dia Mundial do Meio Ambiente”, o "Dia do Índio”, entre outras. As ações coletivas, quando ocorrem, estão focadas na separação do lixo e na identificação das lixeiras coloridas. Quando questionadas sobre porque a escolha de atividades como essas, a justificativa limita-se a "obrigatoriedade de aparecer no planejamento da escola" e ainda, desconhecimento de como fazer de outra maneira. Surge aí uma reflexão importante: parte dos docentes acreditam que a questão ambiental é obrigação de professores de biologia e geografia (LOUREIRO, et al., 2007) e por esse motivo, eles, são a categoria mais presente neste curso. Porém, suas formações por terem ocorrido há mais de vinte anos, como alguns apontam, não contemplaram essas temáticas. Com frequência os cursos abordavam muito mais o conhecimento geral do que temas como os que estão em pauta atualmente: questões de gênero, feminismo e meio ambiente. O meio ambiente quando chega na formação continuada é sempre em formato de palestras, por isso não há tempo para reflexões sobre a prática e sobre metodologias pedagógicas para a abordagem do tema. Neste sentido, compreende-se porque a integração dos conhecimentos é dificil e ainda porque alinhar os elementos subjetivos aos objetivos no tratamento ambiental torna-se complexo.

Com base nessas informações e em conversas informais supomos que os professores tenham dificuldades em lidar com questões relacionadas ao lugar em que estão inseridos. Primeiramente observou-se a dificuldade de responder a questão: em que âmbito espacial agimos? Supondo que uma parte dos docentes são habilitados para aulas de Geografia é surpreendente que nenhum deles reconheça o objeto de estudo desta ciência. Falar e pensar em espaço geográfico é fundamental, pois é neste lugar onde se dão as relações humanas com o meio e é nele que ficam registradas todas as marcas do trabalho coletivo. Como refletiu AB'Saber (1991) as práticas educativas ambientais estão em todos os lugares, e, portanto, poderão ser iniciadas nos diferentes espaços:

[...] Começa em casa. Atinge a rua e a praça. Engloba o bairro. Abrange a cidade ou a metrópole. Ultrapassa as periferias. Repensa o destino dos bolsões de pobreza. Penetra na intimidade dos espaços ditos "opressores". Atinge as peculiaridades e diversidades regionais. Para só, depois, integrar, em mosaico, os espaços nacionais. E, assim colaborar com os diferentes níveis de sanidade exigidos pela escala planetária, dum fragmento de astro que asilou a vida e deu origem aos atributos básicos do ser que pensou o Universo (AB'Saber,1991).

Essa avaliação contribuiu para pensarmos que a prática da EA não refere-se apenas a um trabalho escolar, mas complementa-se com as atividades ali realizadas. No entanto, essa fragilidade conceitual compromete a compreensão de que os problemas ambientais são interdependentes e constituídos por elementos multicausais, como afirmam Rittel e Webber (1973). Neste sentido, a aplicação das políticas públicas de EA fica comprometida. Como vimos, a maioria desconhece sua existência. Assim, apresentamos o documento legal (Lei 9795/99) e focamos na sua análise.

Nesta lei a EA e definida como uma prática que tem por finalidade o processo coletivo de construção de valores sociais para a conservação do meio ambiente para o uso comum. Avaliamos algumas incoerências em relação a sua proposição, como por exemplo, o fato de que a lei estabelece necessidade de trabalho interdisciplinar. No entanto, como sabemos na prática, pela própria estrutura escolar, com os horários dos professores organizados disciplinarmente baseado em um currículo fragmentado, é difícil por em prática o que determina a lei. Um outro 
elemento limitador apontado pelos participantes está nos cursos de formação de professores que pouco tratam do tema EA. Tal informação partiu do próprio grupo, onde profissionais da área de pedagogia e biologia relataram não ter tido qualquer atividade relacionada a EA durante a graduação. Desconhecem o referencial acadêmico sobre esse tema e desconhecem as plataformas de pesquisa ou os principais pesquisadores para buscarem apoio teórico. Há outro fator que é a falta de bibliotecas públicas atualizadas. A internet acaba sendo o único recurso disponível, embora tenha sido relatado a péssima qualidade do sinal ofertado na região.

Um outro aspecto interessante foi o relato de que o grupo nunca relacionou a EA com as tecnologias como propõe a lei. Sendo assim, foram apresentadas experiências com o uso de imagens de satélite, as quais podem ser adquiridas gratuitamente no site do Instituto Nacional de Pesquisas Espaciais. Elas podem ser impressas e usadas na realizazação de trabalhos diversos, como por exemplo, análise do uso das margens dos rios e avaliação do cumprimento do código florestal.

Com as informações acima verificou-se a necessidade de que tanto professores em formação como os que estão em serviço receberem complementação em suas áreas de atuação, com o propósito de atender adequadamente o que prevê os princípios e objetivos da EA. Não apenas por favorecer a abordagem no que se refere as questões ambientais mas, sobretudo, porque contribui para a análise das contradições presentes em nosso espaço vivido.

Os elementos apontados acima refletem a importância das políticas de EA serem cumpridas na escola de modo que possa, de modo transversal no currículo, atender a formação humana considerando os aspectos da sustentabilidade. Como veremos na sequencia, a educação para a sustentabilidade tem um papel importante na formação coletiva.

\section{A Educação para a sustentabilidade}

Algumas questões significativas apareceram durante o curso requerem uma reflexão mais apurada. Primeiro, a escola mantém seu modelo tradicional, baseada no currículo disciplinar e no espaço restrito da sala de aula para a prática do ensino e da aprendizagem. Como apontam alguns estudos, as aulas ao ar livre contribuem para tornar o currículo mais livre, levam os alunos a compreender o ambiente como algo completo e com múltiplas interações (LOPES e PONTUSCHKA, 2009; DILLON e DICKE, 2012). Além disso, contribuem com a saúde física e mental dos envolvidos já que trazem bem estar e os coloca em movimento.

São inúmeros os estudos os quais apontam para os benefícios das experiências sensoriais executadas, por exemplo, ao ar livre. Dentre eles destacamos a possibilidade de estimular o entusiasmo, a curiosidade e a troca de experiências (CORNELL, 1997), favorecem a ênfase no processo de participação, ao espírito cooperativo, a autonomia nas ações e a promoção da autoconfiança (SCHWARTZ, 2004) e ainda melhora da autoestima, da relação com colegas e professores (LAPPIN, 2000).

Evidente que alguns problemas de ordem estrutural são determinantes para a dificuldade em realizar atividades fora da sala de aula, como a falta de estrutura para o deslocamento, o tempo, considerando que alguns professores trabalham em mais do que uma escola e algumas delas distantes entre si. E, conforme relato de um participante, dificuldades no planejamento da atividade (gerenciamento dos objetivos, do tempo e da avaliação das ações realizadas). 
Segundo, a EA continua sendo tratada isoladamente, os problemas ambientais são apontados sem que se amplie as discussões sobre os mesmos. De modo geral, não se trabalha com os grandes temas como biodiversidade, mudanças climáticas, degradação da terra e questões indígenas e quilombolas. A escola continua pautada na questão dos resíduos sólidos sem o tratamento complexo que envolve a produção, o consumo e o uso dos bens naturais. Observou-se que muitos docentes não tiveram a experiência da pesquisa científica em sua formação. Alguns relataram que sequer escreveram um artigo ou monografia, pois na graduação, a avaliação final foi baseada no estágio. Da mesma forma, não participaram de encontros e eventos com pesquisadores da área, exceto naquelas oportunidades ofertadas durante a semana de formação docente (esse dado é alarmante, pois compromete de forma siginificativa a sua formação científica). Portanto, desconhecem os procedimentos mínimos para identificar um problema, a sistematização das informações, a leitura de textos complexos, pois a internet, de certa forma, contribui para checagem de conceitos ou temas muito rapidamente. Neste sentido, há um distanciamento do conhecimento e uma aproximação maior com a informação.

Em terceiro lugar, ficou evidenciado, ao longo dos dez meses de trabalho uma dificuldade muito grande dos professores em discutir e refletir sobre mudanças em suas práticas. Os obstáculos materiais e pessoais para tal mudança são apontados com grande frequência, o que parece denotar uma resistência do grupo a pensar na reorientação do seu trabalho. São apontadas dificuldades para o trabalho coletivo, pois as relações pessoais são frequentemente citadas como um impeditivo para a prática interdisciplinar. Acreditamos que o investimento na educação de forma efetiva é que de fato trará a mudança almejada.

Neste cenário, avaliou-se que a formação de professores precisa ser pensada e adequada ao mundo contemporâneo, isto é, onde o conhecimento se sobreponha a informação. Que as relações pessoais sejam pautadas pelos valores humanos e que o profissionalismo impere sobre as desavenças pessoais, tão presentes nas falas desses participantes. Sabemos que muito do que apareceu está relacionado a falta de valorização social da profissional docente o que os deixa muito angustiados.

Espera-se que os professores possam inserir a EA em suas escolas de modo qualificado, profissional, observando os aspectos relacionados a interdisciplinaridade. Que possam fazer reflexões apuradas sobre o meio no qual estão inseridos, analisando as questões socioambientais presentes, da mesma forma que possam levar seus alunos a compreender o espaço habitado como complexo e pensar em ações para melhoria local.

\section{Conclusão}

Este trabalho é produto de uma análise realizada junto a participantes de um curso de formação continuada sobre Educação Ambiental na educação básica. Em primeiro lugar, buscamos compreender como fazem e o sabem os educadores da rede pública de ensino da região carbonífera do Rio Grande do Sul no que diz respeito a Educação Ambiental.

Como uma atividade extensionista, buscamos aproximação com a comunidade ao ofertar um curso por demanda apresentada por ela. Ao longo de cerca de dez meses, em encontros com duração e cerca de duas horas, ouvimos os participantes em relação as possibilidades e desafios que atravessam as realidades vividas. Apresentamo-lhes não apenas referenciais teóricos, mas alternativas de aplicação da temática educativa ambiental na educação básica. 
Nosso referencial para isto foi pautado na legislação vigente sobre a EA como tema transversal, o saber ambiental e a educação para a sustentabilidade. A pesquisa nos mostrou que há muitos desafios para que, passados quase vinte anos da legislação vigente, ainda seja um grande obstáculo a inserção do tema transversal no currículo escolar. A carga horária pesada junto ao currículo disciplinar impedem que o trabalho seja executado de forma colaborativa.

Os participantes, na maioria professores, mostraram-se abertos à aprendizagem, bem como disposição para implementar novas práticas, entretanto, a realidade na qual estão inseridos impossibilita mudanças de cunho curricular.

Esperamos que atividades como as apresentadas durante a formação, baseadas em valores humanos, em reflexões aprofundadas sobre nossa relação com o consumo e o mundo globalizado possam contribuir, mesmo que a passos menores do que aqueles que almejamos, para uma nova escola no futuro.

\section{Referências}

A'Saber A. N. (Re) conceituando educação ambiental. Disponível em: < http://arquivos. ambiente.sp.gov.br/cea/cea/absaber_reconceituando.pdf>Acesso em agosto de 2010.

\section{DILLON, J. AND DICKIE, I. (2012). Learning in the Natural Environment:} Review of social and economic benefits and barriers. Natural England Commissioned Reports, Number 092. London: Natural England. Disponível em: http://publications. naturalengland.org.uk/publication/1321181. Acesso em março de 2016.

BUBER, M. Eu e'Tu.São Paulo: Cortez \& Moraes, 1974.

CARVALHO, I.C. Educação Ambiental: a formação do sujeito ecológico. 3ed. São Paulo: Cortez, 2008.

CORNELL, J. A alegria de brincar com a natureza: atividades na natureza para todas as idades. São Paulo: SENAC, 1997.

GARCIA, D. S.; PRIOTTO, G. La educacion ambiental como campo de acciónpolíticopedagógico. In: Educación ambiental: aportes políticos y pedagógicos em laconstruccióndel campo de laeducación ambiental. 1ed.: Buenos Aires: Jefatura de Gabinete de Ministros - Presidência de laNacion- Desarrollosustentable, 2009.

H.W.J. RITTEL; M. M. WEBBER, Dilemmas in a General Theory of Planning, Policy Sciences, Vol. 4, No. 2, June 1973, pp. 155-69

LAPPIN, E. Outdoor Education for Behavior Disordered Students. Disponível em:<http://www.kidsource.com/kidsource/content2/outdoor.education.ld.k12.3.html>. Acessoem: 19.jan.2012.

LEFF, E. Saber ambiental: sustentabilidad, racionalidad, complejidad, poder. México: Siglo XXI/UNAM/PNUMA, 1998. 
LOUREIRO, C. F. B., AMORIM E. P., AZEVEDO, L, M., COSSÍO B. Conteúdos, Gestão e Percepção da Educação Ambiental nas Escolas. In: MELLO, S.S de ,TRAJBER, $\mathrm{R}$, (coord). Vamos cuidar do Brasil: conceitos e práticas em educação ambiental na escola 1. - Brasília: Ministério da Educação, Coordenação Geral de Educação Ambiental: Ministério do Meio Ambiente, Departamento de Educação Ambiental: UNESCO, 2007.

MOITA, F. G. S. C; de ANDRADE, F. C. B. Ensino-pesquisa-extensão: um exercício de indissociabilidade na pós-graduação. RevistaBrasileira de Educação v. 14 n. 41 maio/ ago. 2009

Parâmetros curriculares nacionais: introdução aos parâmetros curriculares nacionais / Secretaria de Educação Fundamental. - Brasília : MEC/SEF, 1997. 126p

LOPES, C. S; PONTUSCHKA, N. N. Estudo do meio: teoria e prática.Geografia (Londrina) v. 18, n. 2, 2009 . Disponível em :http://www.uel.br/revistas/uel/index.php/ geografia/ Acesso em março de 2010.

RIBEIRO,I.C.Pedagogia do Alento: paz e sustentabilidade para o século XXI [Apostila do curso Pedagogia do Alento]. Rio Claro: IBEV, 2009.

RIBEIRO, I. C. Educação Ambiental de Corpo\&Alma. In G. Seabra. Educação Ambiental no mundo globalizado. João Pessoa: Editora Universitária UFPB, 2011, p. 39-64.

RIBEIRO, I.C.; SCWHARTZ, G.M. Valores em Transformação: por uma felicidade sustentável. São Paulo: Garcia Edizione, 2017

RIBEIRO, I. C. As Emoções, a felicidade e um planeta chamado água. In: SEABRA, G. (org.) Educação Ambiental, conceitos e aplicações. João Pessoa: Editora da UFPB, 2013, p.151-159.

SANTOS, M. Por uma Geografia Nova. São Paulo: Hucitec, Edusp, 2006.

SCHWARTZ, G.M, Atividades recreativas e Educação Ambiental: uma parceria imbatível, in: SCHUWARTZ, G.M. (org.), Atividades Recreativas. Rio de Janeiro: Guanabara-Koogan, 2004, p. 29, 45. 